\title{
Template-directed proton conduction pathways in a coordination framework
}

\section{AUTHOR(S):}

Inukai, Munehiro; Horike, Satoshi; Chen, Wenqian; Umeyama, Daiki; Itakura, Tomoya; Kitagawa, Susumu

\section{CITATION:}

Inukai, Munehiro ...[et al]. Template-directed proton conduction pathways in a coordination framework. Journal of Materials Chemistry A 2014, 2(27): 10404-10409

\section{ISSUE DATE:}

2014-04-04

URL:

http://hdl.handle.net/2433/199873

\section{RIGHT:}

This journal is (C) The Royal Society of Chemistry 2014.; This is not the published version. Please cite only the published version.; この論文は 出版社版でありません。引用の際には出版社版をご確認ご利用くださ い。 


\title{
Template-directed proton conduction pathway in a coordination framework
}

\author{
Munehiro Inukai, ${ }^{a}$ Satoshi Horike, ${ }^{* b, c}$ Wenqian Chen, ${ }^{b}$ Daiki Umeyama, ${ }^{b}$ Tomoya Itakura, ${ }^{d}$ and Susumu \\ Kitagawa*a,b
}

\author{
s Received (in XXX, XXX) Xth XXXXXXXXX 20XX, Accepted Xth XXXXXXXXX 20XX \\ DOI: 10.1039/b000000x
}

\begin{abstract}
We present a strategy for creating coordination frameworks exhibiting proton conduction with thermal stability. The coordination framework, where template cations link 1-D chains via hydrogen bonds, has dynamic hydrogen bond networks where protons move without water support. Solid-state NMR and X10 ray studies visualized the proton hopping mechanism, and revealed that the templates provide the bridging of the 1-D chains to attain proton conduction. The templates also enable the proton conductive networks to maintain at $190{ }^{\circ} \mathrm{C}$ through multiple interactions between the templates and the 1-D chains.
\end{abstract}

\section{Introduction}

The template-assisted synthesis of crystalline open frameworks, 15 such as zeolites, ${ }^{1-4}$ metal phosphates, ${ }^{5-7}$ and porous coordination polymers/metal organic frameworks $(\mathrm{PCPs} / \mathrm{MOF})^{8-11}$ has been a powerful approach to control crystal structures and porous functions. We can also leave the templates in the frameworks to have functional interplays between the templates and 20 frameworks. ${ }^{12-13}$ The examples of the interplay are the enhancement of thermal stability, ${ }^{14}$ luminescence, ${ }^{15}$ and charge transfer. ${ }^{16}$

On the other hand, the design of effective proton transport in solids has been an attractive challenge in the areas of material 25 chemistry and solid state chemistry. The solid proton conductors are potentially available for electrolytes in fuel cells, gas sensors, and other ionic devices. ${ }^{17-18}$ Although there are many reports on the proton conductors, the structural design is mostly limited on amorphous organic polymers, ${ }^{19-21}$ metal oxides, ${ }^{22-24}$ and 30 oxisoacids. ${ }^{25-27}$ It is important to develop a new structural family of compounds which contributes to the challenge of rational design of proton conduction in solids. ${ }^{28-30}$

In this work, we utilized template cations in coordination frameworks to create proton conduction pathway. As one of 35 platforms for the proton conductors, coordination frameworks, including metal phosphates and PCPs/MOFs, have been attracting attention because of their structural diversity and designability. ${ }^{31-}$

${ }^{33}$ Even though there are many attempts to design proton hopping path in the structures, ${ }^{34-47}$ there is no report on the template-

40 asssisted proton transfer. Here we focus on the incorporated template in coordination frameworks and present a new strategy to attain both proton conductivity and thermal stability. The templates bridge the adjacent coordination frameworks and control hydrogen bond (H-bond) networks to have effective 45 proton conduction pathway in crystal structures. The proton conductive H-bond networks are maintained at $190{ }^{\circ} \mathrm{C}$ through multiple interactions between the templates and the frameworks.

\section{Experimental section}

Synthesis

${ }_{50}$ All chemicals employed were obtained from commercial suppliers and used without further purification. The powder of a coordination framework was synthesized by mixing stoichiometric amounts of zinc oxide (81 $\mathrm{mg}, 1 \mathrm{mmol}$ ), phosphoric acid $(85 \%, 205 \mu \mathrm{L}, 3 \mathrm{mmol})$, and 5,655 dimethylbenzimidazole $(292 \mathrm{mg}, 2 \mathrm{mmol}$ ) as a template with ethanol assist in a mortar for $15 \mathrm{~min}$. The obtained light brown powder was dried at $80{ }^{\circ} \mathrm{C}$ overnight to get dry pure-phase (hereafter 1). Deuterated 1 (1-d) was synthesized using $\mathrm{D}_{3} \mathrm{PO}_{4} / \mathrm{D}_{2} \mathrm{O}(85 \%)$ and $\mathrm{C}_{2} \mathrm{H}_{5} \mathrm{OD}$ instead of normal ones. We also 60 synthesized the powder of a coordination framework by mixing stoichiometric amounts of zinc oxide (81 $\mathrm{mg}, 1 \mathrm{mmol}$ ), phosphoric acid $(85 \%, 205 \mu \mathrm{L}, 3 \mathrm{mmol}), \quad 1,4-$ diazabicyclo[2.2.2] octane $(112 \mathrm{mg}, 1 \mathrm{mmol})$ as a template with ethanol assist in a mortar for $15 \mathrm{~min}$. The obtained white powder ${ }_{65}$ was dried at $80{ }^{\circ} \mathrm{C}$ overnight to get dry pure-phase (hereafter 2) ${ }^{48}$

\section{Physical measurements}

X-ray powder diffraction (XRPD) patterns were collected on a Rigaku RINT 2000 Ultima diffractometer with $\mathrm{CuK} \alpha$ radiation. Thermogravimetry analysis (TGA) was performed using a 70 Rigaku TG8120 under flowing nitrogen with $10 \mathrm{~K} \mathrm{~min}^{-1} \mathrm{ramp}$ rate. Differential scanning calorimetry (DSC) was carried out with a Mettler Toledo DSC822e/200 at the heating rate of $10 \mathrm{~K}$ $\mathrm{min}^{-1}$. Infra-red (IR) spectra were obtained using a Nicolet ID5 ATR operating at room temperature. The adsorption and 75 desorption of $\mathrm{H}_{2} \mathrm{O}$ at $298 \mathrm{~K}$ were measured by BEL-aqua instrument.

Solid state ${ }^{15} \mathrm{~N}$ cross polarization magic angle spinning nuclear magnetic resonance (CPMAS NMR), ${ }^{31} \mathrm{P}$ MAS NMR and ${ }^{2} \mathrm{H}$ quadrupolar echo spectra were recorded on a Bruker ADVANCE 
$400 \mathrm{MHz}$ spectrometer. ${ }^{15} \mathrm{~N}$ CPMAS and ${ }^{31} \mathrm{P}$ MAS spectra were obtained under two-pulse phase modulating (TPPM) proton decoupling. A recycle delay and spinning rate were $5 \mathrm{~s}$ and $6 \mathrm{kHz}$. ${ }^{15} \mathrm{~N}$ and ${ }^{31} \mathrm{P}$ chemical shifts were referenced to $\mathrm{NH}_{4} \mathrm{Cl}$ at 40.7 $5 \mathrm{ppm}$ and phosphoric acid (85\% aqueous solution) at $0 \mathrm{ppm}$. A recycle delay for ${ }^{2} \mathrm{H}$ quadrupolar echo spectra was $10 \mathrm{~s}$.

Single crystal X-ray diffraction measurements were performed at $223 \mathrm{~K}$ using a Rigaku AFC10 diffractometer with Rigaku Saturn Kappa CCD system equipped with a MicroMax-007 10 HF/VariMax rotating-anode X-ray generator with confocal monochromated MoK $\alpha$ radiation. The intensity data at $403 \mathrm{~K}$ were collected on a Rigaku Saturn 724+ CCD diffractometer with graphite-monochromated Mo $\mathrm{K} \alpha$ radiation. The structures were solved by a direct method (SHELXS-97) and refined by full15 matrix least-squares procedures on F2 for all reflections (SHELXL-97). The hydrogen atoms were positioned geometry and refined using a riding model. The deposited numbers of Cambridge Crystallographic Data Centre (CCDC) are 948865 (for 1 at $-50^{\circ} \mathrm{C}$ ) and 948866 (for 1 at $130{ }^{\circ} \mathrm{C}$ ), respectively.

\section{Measurements of ion conductivity and open circuit voltage (OCV)}

For the impedance analysis, the powders (ca. $40 \mathrm{mg}$ ) were pressed at $1000 \mathrm{~kg} \mathrm{~N}$ for 1 minute by a standard $5 \mathrm{~mm}$ diameter and sandwiched two gold electrodes. The thickness of the pellets 25 for compound $\mathbf{1}$ and $\mathbf{2}$ are 1.183 and $0.986 \mathrm{~mm}$. AC Impedance measurements were recorded using a Solartron SI 1260 Impedance/Gain-Phase analyzer over frequency range $1 \mathrm{~Hz}-1$ $\mathrm{MHz}$ with input voltage amplitude of $30 \mathrm{mV}$. To dry pellets and confirm thermal stability, the pellets of $\mathbf{1}$ and $\mathbf{2}$ were heated and 30 maintained at 190 and $150{ }^{\circ} \mathrm{C}$ under $\mathrm{N}_{2}$ atmosphere in a cell. After heating the pellets, we carried out the measurements for both cooling and heating regimes under $\mathrm{N}_{2}$ atmosphere in the cell. ZView software was used for fitting of impedance profiles by means of an equivalent circuit to obtain the resistance values. In 35 the Nyquis plots, the bulk and grain boundary could not be resolved. We used a single parallel RC circuit to fit the data. To measure OCV, a membrane electrode assembly (MEA) was prepared following procedure. Powder of 1 was sandwiched between two platinum-loaded carbon electrodes. The MEA was 40 set in a hole punched at a PTFE sheet as gasket. Two gas chambers were set up by placing the PTFE sheet between stainless steel flanges. Dry $\mathrm{H}_{2}$ gas $\left(100 \mathrm{~mL} \mathrm{~min}^{-1}\right)$ and dry air $\left(100 \mathrm{~mL} \mathrm{~min}{ }^{-1}\right)$ were supplied to the chamber.

\section{Results and discussion}

\section{${ }_{45}$ Crystal structures}

To reveal the crystal structure, we made a single crystal and performed an X-ray diffraction measurement at $-50{ }^{\circ} \mathrm{C}$. As shown in Fig. 1a, the single crystal structure has a composition of $\left[\mathrm{Zn}\left(\mathrm{H}_{2} \mathrm{PO}_{4}\right)_{2}\left(\mathrm{HPO}_{4}\right)\right] \cdot\left(\mathrm{H}_{2} \mathrm{dmbim}\right)_{2} \quad(\mathbf{1}) ;\left(\mathrm{H}_{2} \mathrm{dmbim}=\right.$ protonated 50 form of 5,6-dimethylbenzimidazole). The protonated $\mathrm{H}_{2} \mathrm{dmbim}$ $\left(\mathrm{H}_{2} \mathrm{dmbim}^{+}\right)$was confirmed by ${ }^{15} \mathrm{~N}$ solid-state NMR and IR spectrum (Fig. S9, S11). It consists of an anionic one-dimensional (1-D) chain of $\mathrm{Zn}^{2+}$ and phosphates along the $b$ axis, and $\mathrm{H}_{2} \mathrm{dmbim}^{+}$as templates. The $\mathrm{Zn}^{2+}$ ion has a tetrahedral 55 coordination environment. $\mathrm{H}_{2} \mathrm{PO}_{4}{ }^{-}$and $\mathrm{HPO}_{4}{ }^{2-}$ groups coordinate to the $\mathrm{Zn}^{2+}$ ion in monodentate fashion, and another bidentate
$\mathrm{HPO}_{4}{ }^{2-}$ functions as a linker for the $\mathrm{Zn}^{2+}$ ions to form the anionic 1-D zinc phosphate chain $\left(\mathrm{Zn}\left(\mathrm{H}_{2} \mathrm{PO}_{4}\right)_{2}\left(\mathrm{HPO}_{4}\right)^{2-}\right)$. From the $b$ axis in Fig. $1 b$, it can be seen that the $\mathrm{H}_{2} \mathrm{dmbim}^{+}$ions are closely 60 packed with $\pi-\pi$ stacking parallel to the $a$ axis where the distance between the $\mathrm{H}_{2} \mathrm{dmbim}^{+}$ions is $3.5 \AA$
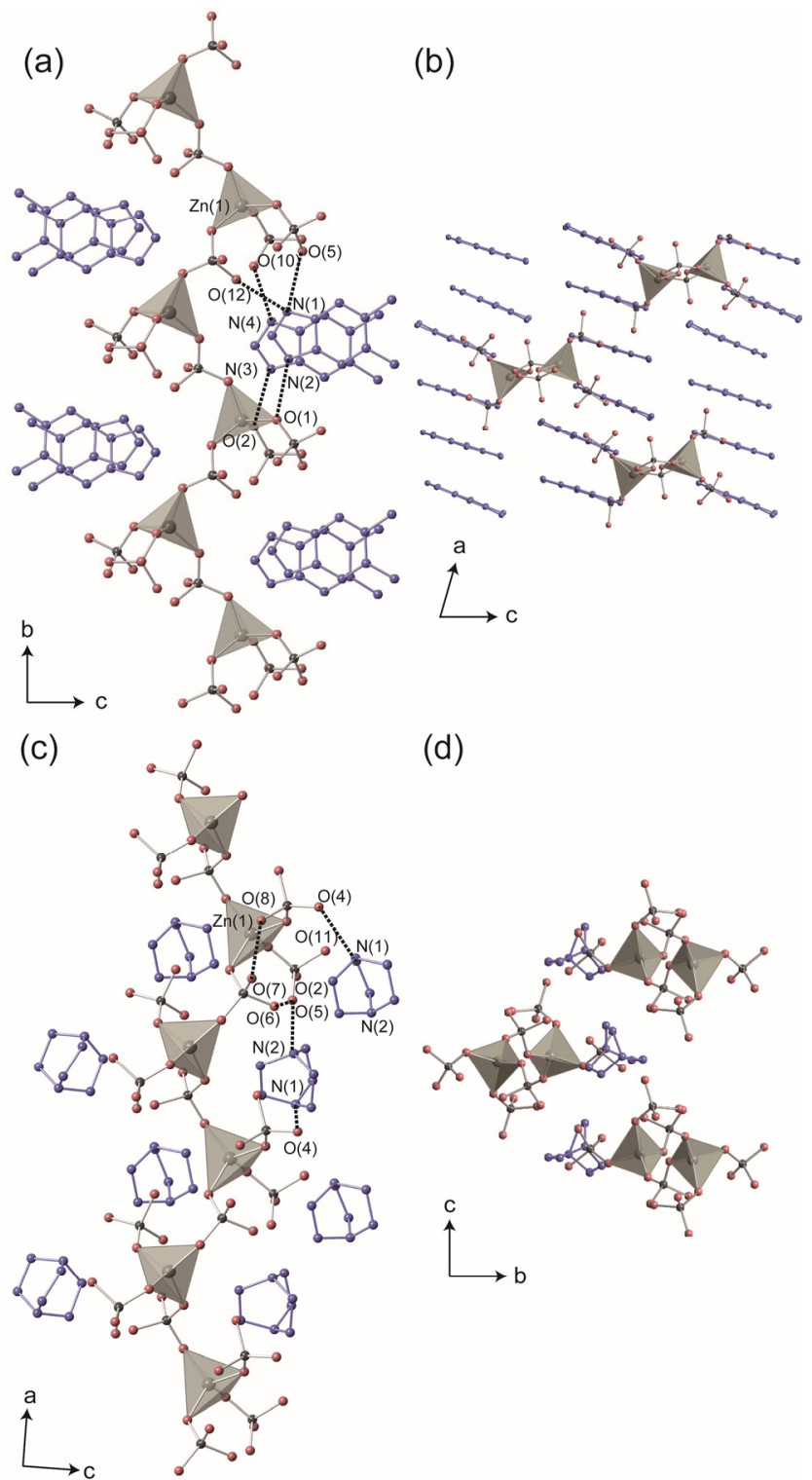

Fig. 1 (a) Crystal structure of $\left[\mathrm{Zn}\left(\mathrm{H}_{2} \mathrm{PO}_{4}\right)_{2}\left(\mathrm{HPO}_{4}\right)\right] \cdot\left(\mathrm{H}_{2} \mathrm{dmbim}\right)_{2}$ (1) along the $a$ axis and (b) the $b$ axis at $-50^{\circ} \mathrm{C}$. (c) Crystal structure of

${ }_{65}\left[\mathrm{Zn}\left(\mathrm{H}_{2} \mathrm{PO}_{4}\right)_{2}\left(\mathrm{HPO}_{4}\right)\right] \cdot \mathrm{H}_{2} \mathrm{dabco}(2)$ along the $b$ axis and (d) the $a$ axis at $-50{ }^{\circ} \mathrm{C}$. The $\mathrm{H}_{2} \mathrm{dmbim}^{+}$ions and $\mathrm{H}_{2} \mathrm{dabco}^{2+}$ ions are highlighted as purple and hydrogen atoms are omitted. H-bonds between the 1-D chain and $\mathrm{H}_{2} \mathrm{dmbim}^{+}$and $\mathrm{H}_{2} \mathrm{dabco}^{2+}$ are shown as black dotted lines. [Color coding: Gray: $\mathrm{Zn}$ and $\mathrm{P}$, pink: $\mathrm{O}$, purple: $\mathrm{N}$ and $\mathrm{C}$.]

70 To elucidate template impact on thermal stability and proton conduction, we also employed on $\left[\mathrm{Zn}\left(\mathrm{H}_{2} \mathrm{PO}_{4}\right)_{2}\left(\mathrm{HPO}_{4}\right)\right] \cdot \mathrm{H}_{2}$ dabco (2); $\left(\mathrm{H}_{2}\right.$ dabco $=$ diprotonated form of 1,4diazabicyclo[2.2.2] octane) which has similar anionic 1-D zincphosphate chain, but different shape and size of cationic template. 75 The crystal structure of 2 was reported previously. ${ }^{48}$ Fig. 1c and $1 \mathrm{~d}$ shows the structure composed of $\left(\mathrm{Zn}\left(\mathrm{H}_{2} \mathrm{PO}_{4}\right)_{2}\left(\mathrm{HPO}_{4}\right)^{2-}\right)$ as the 1-D chain and a diprotonated $\mathrm{H}_{2}$ dabco $\left(\mathrm{H}_{2} \mathrm{dabco}^{2+}\right)$ as the cationic 
template. Contrast to the $\pi-\pi$ stacking between the plate-shaped $\mathrm{H}_{2} \mathrm{dmbim}^{+}$in $\mathbf{1}$, there is no interaction between the neighboring spherical $\mathrm{H}_{2} \mathrm{dabco}^{2+}$ in 2. Mutual stacking of the $\mathrm{H}_{2} \mathrm{dmbim}^{+}$is expected to induce the thermal stabilization of the crystal 5 structure.

\section{Thermal stability}

To investigate the thermal stability of the crystal structures, we measured variable temperature X-ray powder diffraction (XPRD) patterns under $\mathrm{N}_{2}$ atmosphere. In the case of 1 , obtained XPRD 10 patterns in $40-190{ }^{\circ} \mathrm{C}$ do not change, suggesting that the crystal structure is intact up to $190{ }^{\circ} \mathrm{C}$ (Fig. S4). This high thermostability is owing to the multiple interactions between the chain and the templates. The XRPD patterns of 2 in $28-160{ }^{\circ} \mathrm{C}$ do not change. However, the extra peaks start to appear at $180^{\circ} \mathrm{C}$, 15 suggesting structural transformation or decomposition (Fig. S5, S6). The weaker interaction of the 1-D chain and the templates in 2 causes lower thermal stability compared with that of $\mathbf{1}$. Accordingly, TGA, DSC, and XRD studies (Fig. S7, S8) revealed that the crystal structures of $\mathbf{1}$ and $\mathbf{2}$ are retained until $190^{\circ} \mathrm{C}$ and $20160{ }^{\circ} \mathrm{C}$, respectively.

\section{Water stability}

We also evaluated the structural stability of $\mathbf{1}$ and $\mathbf{2}$ against humidity because high water stability is widely required for various applications, including fuel cells and gas sensors. ${ }^{49-51}$ The

25 powders of $\mathbf{1}$ and $\mathbf{2}$ were exposed to $80{ }^{\circ} \mathrm{C}$ and $80 \%$ relative humidity for $48 \mathrm{~h}$ in a thermo-hygrostat. The powders of $\mathbf{1}$ and $\mathbf{2}$ were intact without any dissociation, and the observed XRD patterns after the humidity exposure were same as those of the initial states (Fig. S3, S5). This indicates that the crystal 30 structures of $\mathbf{1}$ and $\mathbf{2}$ are stable against the high humid condition.

\section{Anhydrous proton conduction}

To investigate proton conductivities, we carried out alternate current impedance spectroscopy under anhydrous $\mathrm{N}_{2}$ atmosphere. Fig. 2a shows Arrhenius plots of the anhydrous proton 35 conductivities for both compounds. The conductivity of 1 reaches $0.2 \mathrm{mS} \mathrm{cm}{ }^{-1}$ at $190{ }^{\circ} \mathrm{C}$. The conductivity of $\mathbf{1}$ at $190{ }^{\circ} \mathrm{C}$ was unchanged over $3 \mathrm{~h}$ (Fig. S14). This operating temperature is among the highest for reported coordination frameworks, including metal phosphates and CPs/MOFs..$^{32-34,42}$ The calculated 40 activation energy is $0.66 \mathrm{eV}$ in $110-190{ }^{\circ} \mathrm{C}$, suggesting that the main proton hopping mechanism is probably the Grotthus mechanism. ${ }^{17}$ On the other hand, 2 shows lower conductivity $\left(0.08 \mu \mathrm{S} \mathrm{cm}^{-1}\right.$ at $\left.160{ }^{\circ} \mathrm{C}\right)$ and higher activation energy $(1.2 \mathrm{eV})$. The difference between the templates strongly affects the 45 conductivity and the activation energy. This template effect on proton conduction will be discussed later.
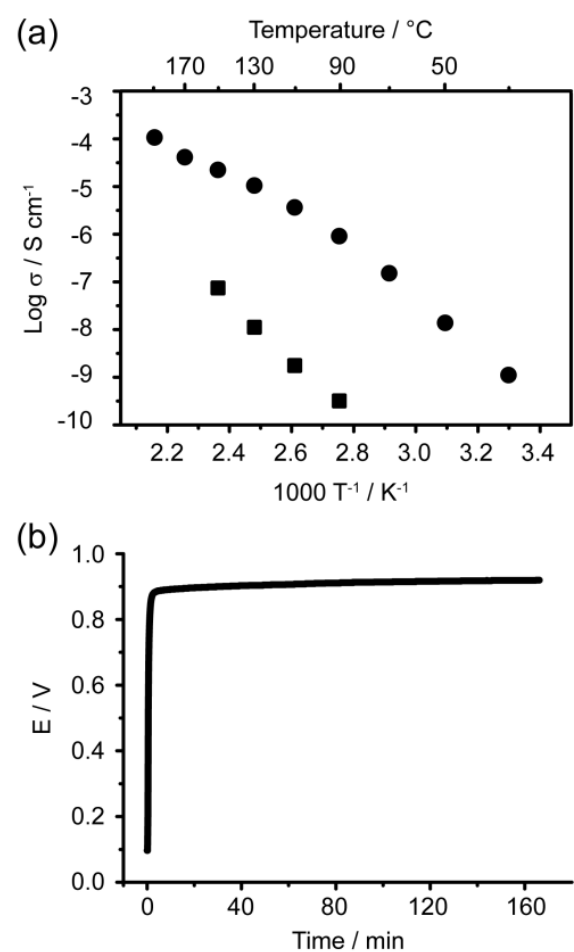

Fig. 2 (a) Arrhenius plots of anhydrous conductivity of 1 in $30-190{ }^{\circ} \mathrm{C}$ (circle) and 2 in $90-150{ }^{\circ} \mathrm{C}$ (square). (b) Open circuit voltage in a $\mathrm{H}_{2} /$ air 50 cell at $190{ }^{\circ} \mathrm{C}$, where the electrolyte is $\mathbf{1}$.

We fabricated a membrane electrode assembly with pelletized $\mathbf{1}$ and measured electromotive force to confirm conductive species $\left(\mathrm{H}^{+}\right.$or other). The observed open circuit voltage $(\mathrm{OCV})$ in a $\mathrm{H}_{2}$ /air cell is $0.92 \mathrm{~V}$ at anhydrous $190{ }^{\circ} \mathrm{C}$ for over $2.5 \mathrm{~h}$ (Fig. 2b). ${ }_{55}$ This result suggests that dominant conductive species are protons and the protons transport from anode to cathode through H-bond networks in the pellet of 1 . The OCV value is slightly lower than the theoretical maximum, which is $1.14 \mathrm{~V}$ at $190{ }^{\circ} \mathrm{C}$ under $1 \mathrm{~atm}$; however, the stable and high value indicates that fuel crossover 60 and unfavorable reactions between 1 and the electrodes do not occur owing to their dense crystal structure.

\section{Proton hopping mechanism}

For the proton hopping in coordination frameworks, both proton transfer steps in H-bond networks and dynamics of proton ${ }_{65}$ carriers are essential. ${ }^{18}$ In the case of $\mathbf{1}$, while the multiple Hbonds between the chain and the templates provide thermal stability of the crystal structure, optimized H-bonds between the neighboring chains offer an effective anhydrous proton hopping pathway. Fig. 3a shows the proton hopping pathway along the $a$ 70 axis through the monodentate $\mathrm{H}_{2} \mathrm{PO}_{4}{ }^{-}$and $\mathrm{HPO}_{4}{ }^{2-}$. The H-bond distances of $\mathrm{O}(5)-\mathrm{O}(9), \mathrm{O}(6)-\mathrm{O}(7)$, and $\mathrm{O}(8)-\mathrm{O}(9)$ are 2.53, 2.55, and $2.58 \AA$, respectively. These distances are close to optimized proton hopping distance according to the theoretical calculation of potential energy of orthophosphate rotation. ${ }^{52}$ 

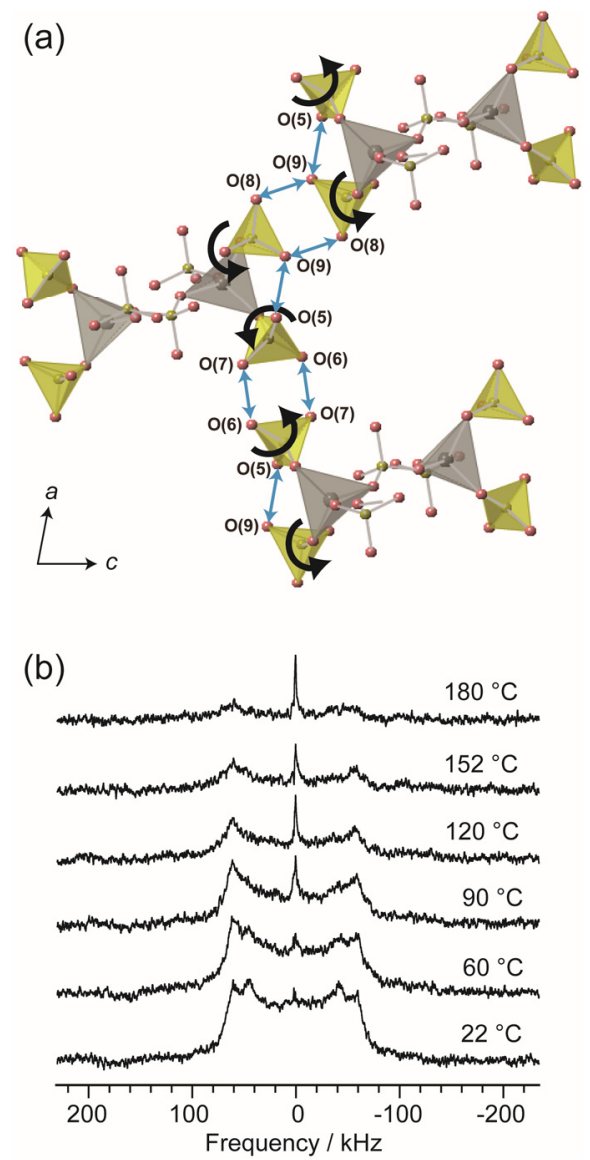

Fig. 3 (a) Proton hopping pathway through H-bond networks and rotation of monodentate $\mathrm{H}_{2} \mathrm{PO}_{4}{ }^{-}$and $\mathrm{HPO}_{4}{ }^{2-}$ in $\mathbf{1}$. The monodentate phosphates are represented by yellow tetrahedral blocks. Blue and black arrows 5 indicate the $\mathrm{H}$-bonds and reorientation, respectively. (b) ${ }^{2} \mathrm{H}$ solid-state NMR spectra of deuterated $\mathbf{1}$ in $22-180^{\circ} \mathrm{C}$.

To confirm the rotation of the monodentate phosphates in $\mathbf{1}$, we measured ${ }^{2} \mathrm{H}$ solid-state NMR of deuterated 1 (1-d), where the monodentate and the bidentate phosphates were deuterated. Fig. $103 \mathrm{~b}$ shows quadrupolar-echo ${ }^{2} \mathrm{H}$ NMR spectra of 1-d in $22-180{ }^{\circ} \mathrm{C}$. The spectrum at $22{ }^{\circ} \mathrm{C}$ shows small sharp isotropic peak at the center and two types of characteristic Pake patterns with quadrupolar splitting of 123 and $93 \mathrm{kHz}$. With increasing temperature, the intensities of the Pake patterns decrease, and the 15 intensity of the isotropic peak increases. This indicates that the fast rotations of the phosphates occur above $90{ }^{\circ} \mathrm{C} .{ }^{53} \mathrm{We}$ also collected single crystal X-ray data of 1 at $130{ }^{\circ} \mathrm{C}$. Even at high temperature, where proton conduction occurs $\left(10^{-5} \mathrm{~S} \mathrm{~cm}^{-1}\right.$ at $130{ }^{\circ} \mathrm{C}$ ), we do not observe the disordering of the $\mathrm{H}_{2} \mathrm{dmbim}^{+}$ions 20 and the phosphates. This indicates that the monodentate phosphates have a either rigid state or 3-fold rotation, and the templates do not move in a wide temperature range.

Considering the suggestive fast rotation of the phosphates by ${ }^{2} \mathrm{H}$ solid-state NMR, a plausible explanation for the isotropic peak at 25 the center is the fast 3 -fold rotation of the monodentate phosphates. On the basis of the investigation, main proton transport occurs in the monodentate phosphates with fast 3-fold rotation, as shown in Fig. 3a. In addition, the $\mathrm{H}_{2} \mathrm{dmbim}^{+}$ions and the bidentate phosphate, which have H-bonds to the monodentate 30 phosphates, would support the proton transport pathway.
The template effect on proton conduction is illustrated in Scheme 1. For both compounds, the rotatable monodentate phosphates play the primary role in proton transport, and extended H-bonds via the phosphates are required. In this sense, 35 the assembly of $\mathrm{H}_{2} \mathrm{dmbim}^{+}$ions determines the alignment of 1-D chains of zinc phosphates in $\mathbf{1}$, which provides the effective proton hopping path along the $a$ axis. On the other hand, the zinc phosphate chains in $\mathbf{2}$ are assembled in an interdigitated manner because of the shape and size of $\mathrm{H}_{2} \mathrm{dabco}^{2+}$ ions. Consequently, 40 the monodentate phosphates are isolated in $\mathbf{2}$, inducing the lower conductivity.

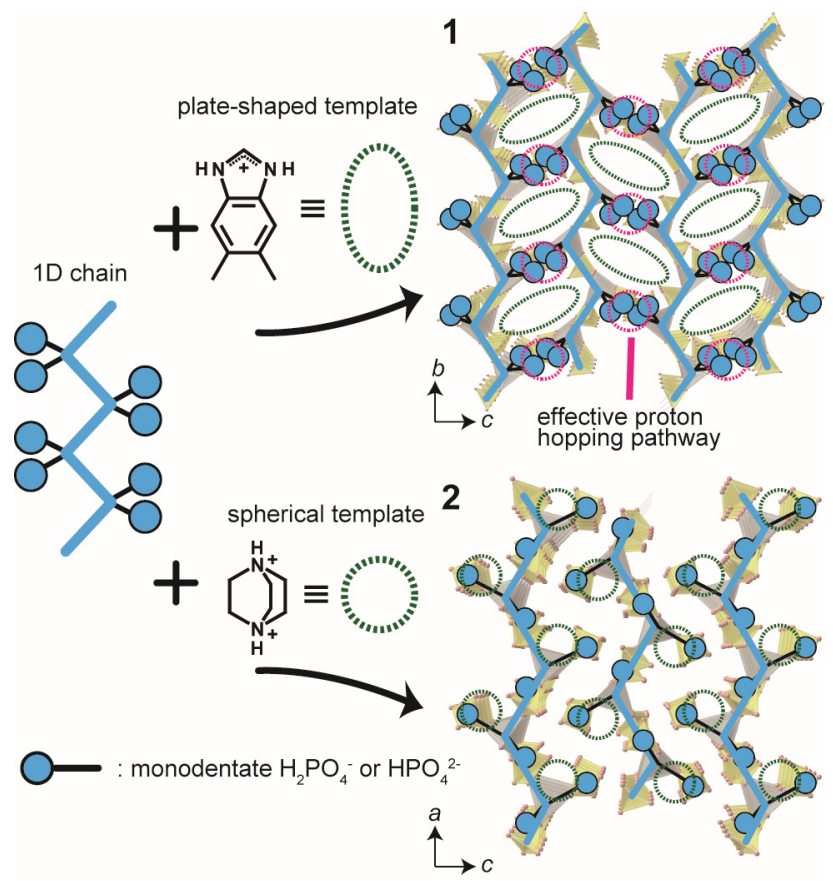

Scheme 1 Schematic illustration of template effects on the crystal structure and proton conduction of $\mathbf{1}$ and $\mathbf{2}$. The $\mathrm{H}_{2} \mathrm{dmbim}^{+}$and $\mathrm{H}_{2} \mathrm{dabco}^{2+}$ 45 ions are omitted. Green and pink dotted circles represent the position of templates and effective proton hopping pathways.

\section{Conclusions}

We proposed a new strategy for creating proton conducting pathway with thermal stability in coordination frameworks. ${ }_{50}$ Templates in the frameworks control alignment the 1-D coordination chains and provide proton conductive H-bond networks. Multiple interactions between the templates and the frameworks impart thermal and water stability. Solid-state NMR and X-ray studies visualized the proton hopping mechanism, and 55 revealed the template effect on the proton transport. The observed thermal and water stability in the proton conductive frameworks offers opportunities for the development of new ion conductive materials. ${ }^{54-56}$

\section{Acknowledgements}

${ }_{60}$ This work was supported by the Japan Science and Technology Agency PRESTO Program, Grants-in-Aid for Scientific Research, and the Japan Society for the Promotion of Science (JSPS). iCeMS is supported by the World Premier International Research Center Initiative (WPI), MEXT, Japan. 


\section{Notes and references}

${ }^{a}$ Institute for Integrated Cell-Material Sciences (iCeMS), Kyoto University, Yoshida, Sakyo-ku, Kyoto 606-8501, Japan. E-mail: kitagawa@icems.kyoto-y.ac.jp

$5^{b}$ Department of Synthetic Chemistry and Biological Chemistry, Graduate School of Engineering, Kyoto University, Katsura, Nishikyo-ku, Kyoto 615-8510, Japan.E-mail: horike@sbchem.kyoto-u.ac.jp

c Japan Science and Technology Agency, PRESTO, 4-1-8, Honcho, Kawaguchi, Saitama 332-0012, Japan

$10{ }^{d}$ DENSO CORPORATION, 1-1 Showa-cho, Kariya, Aichi 448-8661,

Japan

$\dagger$ Electronic Supplementary Information (ESI) available: single crystal structures, XRD patterns, TGA profiles, DSC profiles, solid-state NMR spectra, IR spectra, adsorption isoterm, and AC impedance measurements. 15 See DOI: $10.1039 / \mathrm{b} 000000 \mathrm{x} /$

1. R. H. Daniels, G. T. Kerr and L. D. Rollmann, J. Am. Chem. Soc., 1978, 100, 3097-3100.

2. M. E. Davis and R. F. Lobo, Chem. Mater., 1992, 4, 756-768.

3. R. Simancas, D. Dari, N. Velamazán, M. T. Navarro, A. Cantín, J. L.

20 Jordá, G. Sastre, A. Corma and F. Rey, Science, 2010, 330, 12191222 .

4. N. Stock, Microporous Mesoporous Mater., 2010, 129, 287-295.

5. A. K. Cheetham, G. Ferey and T. Loiseau, Angew. Chem. Int. Ed., 1999, 38, 3268-3292.

25 6. R. Murugavel, A. Choudhury, M. G. Walawalkar, R. Pothiraja and C. N. R. Rao, Chem. Rev., 2008, 108, 3549-3655.

7. S. Natarajan and S. Mandal, Angew. Chem. Int. Ed., 2008, 47, 47984828 .

8. D. Tanaka and S. Kitagawa, Chem. Mater., 2008, 20, 922-931.

30 9. J.-P. Zhang, Y.-B. Zhang, J.-B. Lin and X.-M. Chen, Chem. Rev., 2011, 112, 1001-1033.

10. Z. Zhang, L. Zhang, L. Wojtas, P. Nugent, M. Eddaoudi and M. J. Zaworotko, J. Am. Chem. Soc., 2011, 134, 924-927.

11. B. Manna, A. K. Chaudhari, B. Joarder, A. Karmakar and S. K. Ghosh, Angew. Chem. Int. Ed., 2013, 52, 998-1002.

12. D. T. de Lill, N. S. Gunning and C. L. Cahill, Inorg. Chem., 2005, 44, 258-266.

13. R. Sekiya and S.-i. Nishikiori, Chem. Commun., 2012, 48, 5022-5024.

14. Y.-C. Liao, Y.-C. Jiang and S.-L. Wang, J. Am. Chem. Soc., 2005, 127, 12794-12795.

15. K. Jayaramulu, P. Kanoo, S. J. George and T. K. Maji, Chem. Commun., 2010, 46, 7906-7908.

16. S. Yamanaka, K.-i. Hotehama and H. Kawaji, Nature, 1998, 392, $580-582$.

45 17. K.-D. Kreuer, Chem. Mater., 1996, 8, 610-641.

18. K.-D. Kreuer, S. J. Paddison, E. Spohr and M. Schuster, Chem. Rev., 2004, 104, 4637-4678.

19. M. A. Hickner, H. Ghassemi, Y. S. Kim, B. R. Einsla and J. E. McGrath, Chem. Rev., 2004, 104, 4587-4612.

50 20. H. Steininger, M. Schuster, K. D. Kreuer, A. Kaltbeitzel, B. Bingol, W. H. Meyer, S. Schauff, G. Brunklaus, J. Maier and H. W. Spiess, Phys. Chem. Chem. Phys., 2007, 9, 1764-1773.

21. H. Zhang and P. K. Shen, Chem. Rev., 2012, 112, 2780-2832.

22. K. D. Kreuer, Solid State Ionics, 1999, 125, 285-302.

55 23. T. Norby, M. Wideroe, R. Glockner and Y. Larring, Dalton Trans., 2004, 3012-3018

24. E. Fabbri, D. Pergolesi and E. Traversa, Chem. Soc. Rev., 2010, 39, 4355-4369.

25. B. V. Merinov, Solid State Ionics, 1996, 84, 89-96.

60 26. G. Alberti and M. Casciola, Solid State Ionics, 2001, 145, 3-16.

27. S. M. Haile, D. A. Boysen, C. R. I. Chisholm and R. B. Merle, Nature, 2001, 410, 910-913.

28. R. Devanathan, Energy Environ. Sci., 2008, 1, 101-119.

29. C. Laberty-Robert, K. Valle, F. Pereira and C. Sanchez, Chem. Soc. Rev., 2011, 40, 961-1005.

30. Y. Wang, K. S. Chen, J. Mishler, S. C. Cho and X. C. Adroher, Appl. Energy, 2011, 88, 981-1007.

31. G. Alberti, M. Casciola, U. Costantino and R. Vivani, Adv. Mater., 1996, 8, 291-303.
70 32. S. Horike, D. Umeyama and S. Kitagawa, Acc. Chem. Res., 2013, 46 2376-2384

33. M. Yoon, K. Suh, S. Natarajan and K. Kim, Angew. Chem. Int. Ed., 2013, 52, 2688-2700.

34. G. Alberti, U. Costantino, M. Casciola, R. Vivani and A. Peraio, Solid State Ionics, 1991, 46, 61-68

35. H. Kitagawa, Y. Nagao, M. Fujishima, R. Ikeda and S. Kanda, Inorg. Chem. Commun., 2003, 6, 346-348.

36. S. Bureekaew, S. Horike, M. Higuchi, M. Mizuno, T. Kawamura, D Tanaka, N. Yanai and S. Kitagawa, Nat. Mater., 2009, 8, 831-836.

80 37. J. A. Hurd, R. Vaidhyanathan, V. Thangadurai, C. I. Ratcliffe, I. L. Moudrakovski and G. K. H. Shimizu, Nat. Chem., 2009, 1, 705-710.

38. N. C. Jeong, B. Samanta, C. Y. Lee, O. K. Farha and J. T. Hupp, J. Am. Chem. Soc., 2011, 134, 51-54.

39. D. Umeyama, S. Horike, M. Inukai, Y. Hijikata and S. Kitagawa, Angew. Chem. Int. Ed., 2011, 50, 11706-11709.

40. M. Sadakiyo, H. Ōkawa, A. Shigematsu, M. Ohba, T. Yamada and H. Kitagawa, J. Am. Chem. Soc., 2012, 134, 5472-5475.

41. S. Sen, N. N. Nair, T. Yamada, H. Kitagawa and P. K. Bharadwaj, $J$. Am. Chem. Soc., 2012, 134, 19432-19437.

90 42. G. K. H. Shimizu, J. M. Taylor and K. W. Dawson, Metal Phosphonate Chemistry: From Synthesis to Applications, The Royal Society of Chemistry, 2012, 493-524.

43. M. Feyand, C. F. Seidler, C. Deiter, A. Rothkirch, A. Lieb, M. Wark and N. Stock, Dalton Trans., 2013, 42, 8761-8770.

95 44. S. Horike, Y. Kamitsubo, M. Inukai, T. Fukushima, D. Umeyama, T. Itakura and S. Kitagawa, J. Am. Chem. Soc., 2013, 135, 4612-4615.

45. X. Liang, F. Zhang, W. Feng, X. Zou, C. Zhao, H. Na, C. Liu, F. Sun and G. Zhu, Chem. Sci., 2013, 4, 983-992.

46. J. M. Taylor, K. W. Dawson and G. K. H. Shimizu, J. Am. Chem. Soc., 2013, 135, 1193-1196.

47. P. Ramaswamy, R. Matsuda, W. Kosaka, G. Akiyama, H. J. Jeon and S. Kitagawa, Chem. Commun., 2014, 50, 1144-1146.

48. J. Patarin, B. Marler and L. Huve, Eur. J. Solid State Inorg. Chem., 1994, L31, 909-920.

105 49. D. A. Boysen, T. Uda, C. R. I. Chisholm and S. M. Haile, Science, 2004, 303, 68-70.

50. B. R. Einsla, Y. S. Kim, M. A. Hickner, Y.-T. Hong, M. L. Hill, B. S. Pivovar and J. E. McGrath, J. Membr. Sci., 2005, 255, 141-148.

51. C.-C. Lin, C.-B. Chang and Y.-Z. Wang, J. Power Sources, 2013, 223, 277-283.

52. S. J. Paddison, K.-D. Kreuer and J. Maier, Phys. Chem. Chem. Phys., 2006, 8, 4530-4542.

53. Y. J. Lee, T. Murakhtina, D. Sebastiani and H. W. Spiess, J. Am. Chem. Soc., 2007, 129, 12406-12407.

115 54. Q. Li, R. He, J. O. Jensen and N. J. Bjerrum, Chem. Mater., 2003, 15, 4896-4915.

55. J. A. Asensio, E. M. Sanchez and P. Gomez-Romero, Chem. Soc. Rev., 2010, 39, 3210-3239.

56. A. Chandan, M. Hattenberger, A. El-kharouf, S. Du, A. Dhir, V. Self, B. G. Pollet, A. Ingram and W. Bujalski, J. Power Sources, 2013, 231, 264-278. 